\title{
A Patient with Breast Fibroadenoma Accompanied by Carcinoma: Early Detection by Monitoring.
}

\section{Katsuhisa Enomoto}

Nihon Daigaku Igakubu Fuzoku Itabashi Byoin

\section{Yukiko Hara}

Nihon Daigaku Igakubu Fuzoku Itabashi Byoin

\section{Kazuyoshi Dobashi}

Senkawa OB/GYN and Breast Clinic

\section{Shinobu Masuda}

Nihon Daigaku Igakubu Fuzoku Itabashi Byoin

Keiichiro Tada ( $\square$ tada.keiichiro@nihon-u.ac.jp)

Nihon Daigaku Byoin https://orcid.org/0000-0002-5395-986X

\section{Research Article}

Keywords: fibroadenoma, breast neoplasm, diagnosis, case report

Posted Date: February 24th, 2021

DOI: https://doi.org/10.21203/rs.3.rs-246535/v1

License: (c) (1) This work is licensed under a Creative Commons Attribution 4.0 International License. Read Full License 


\section{Abstract}

Background: A complex breast lesion comprising both fibroadenoma and carcinoma is very challenging to diagnose early in the disease.

Case Presentation: The patient was a 76-year-old woman who was followed at our clinic for 8 years because of a 7-mm tumor, which was determined to be fibroadenoma on a core needle biopsy specimen. However, another core needle biopsy was performed because part of the margin of the tumor was obscure. A histopathological examination revealed that the second specimen contained malignant cells. The patient underwent breast-conserving surgery and a sentinel lymph node biopsy. The histopathological examination found both breast carcinoma and fibroadenoma, with some of the 2 lesions overlapping. The sentinel lymph node specimen showed micrometastases. The patient's postoperative course was uneventful.

Conclusions: The findings in our patient suggest that careful examination of the margin of the breast fibroadenoma was essential for early detection of the breast carcinoma.

\section{Introduction}

Fibroadenoma is a common benign tumor of the breast. This benign breast tumor has been reported to affect $25 \%$ of asymptomatic women [1]. This tumor does not metastasize, and it is not usually treated unless it grows larger.

Many published reports describe cases of breast cancer associated with a fibroadenoma. Some reports describe patients with a breast cancer that has developed within a fibroadenoma [2-4] and patients with a breast cancer that has developed in the vicinity of a fibroadenoma $[5,6]$. However, whether a patient with breast fibroadenoma has an increased risk of breast cancer is controversial $[7,8]$.

Obtaining the diagnosis of breast cancer accompanied by a fibroadenoma is a great challenge. Breast fibroadenomas impede the early detection of breast cancer. Indicators that are thought to suggest a cancerous lesion accompanied by a fibroadenoma include enlarged, irregular masses with indistinct margins and abnormal calcifications $[9,10]$. However, most cases of breast fibroadenoma associated with carcinoma are discovered when the breast mass enlarges [2, 4-6].

In this report, we describe a woman with a 5-mm malignant breast tumor that developed in association with the margin of a 7-mm fibroadenoma. Careful examination of the tumor margin is essential for early detection.

\section{Case Presentation}

The patient was a 76-year-old woman who was followed by our clinic for 8 years because of 7-mm breast tumor, which was determined to be a fibroadenoma based on examination of a core needle biopsy 
specimen. A follow-up ultrasound showed that the margin of the tumor was obscure. Therefore, another core needle biopsy was performed. A histopathological examination of the second biopsy specimen revealed a cancerous lesion. The patient was referred to our department for further treatment. Her past medical history was unremarkable except for hypertension. She had a negative family history for breast cancer and ovarian cancer. A breast physical examination was negative for an abnormal mass in either of her breasts. Swollen lymph nodes were not palpated in either axilla. Mammography showed that her affected breast was heterogeneously dense without abnormal findings. Ultrasonography revealed a 10$\mathrm{mm}$ hypoechoic tumor (Figure 1). One part of the tumor showed echogenicity that was different from the other part of the tumor, and also showed obscured margins. Contrast-enhanced magnetic resonance imaging revealed an oval tumor divided into 2 parts based on different vascularities (Figure 2). A review of the processed specimen confirmed an invasive adenocarcinoma. We concluded that the patient had early breast cancer. She underwent breast-conserving surgery and a sentinel lymph node biopsy. The histopathological examination showed both a carcinoma and a fibroadenoma, which partially overlapped (Figure 3). A sentinel lymph node was found to have micrometastatic disease. Immunohistochemically processed slides were estrogen receptor-positive, progesterone receptor-negative, and HER2-negative, with a low Ki67 score. The patient's postoperative course was uneventful. She received radiation and endocrine therapy.

\section{Discussion}

We presented a patient with a 5-mm breast cancer that developed in the margins of 7-mm fibroadenoma. Early detection of a breast malignancy that is closely associated with a fibroadenoma is difficult. However, we were able to identify an early breast malignancy by examining the margin of the mass that contained both the fibroadenoma and the malignant breast tissue.

Early identification of a breast cancer that develops within a fibroadenoma near it is a major challenge. The presence of the fibroadenoma delays an early discovery of the cancer. Many patients therefore are only discovered to have a breast malignancy when enlargement of the tumor is noticed $[4,6]$. When a breast cancer is discovered because of its enlarging size, time will have elapsed while the tumor grows before the diagnosis; and avoiding such a situation is preferred.

A pleomorphic microcalcification seen on mammography is a major clue that can allow early detection of a breast cancer associated with fibroadenoma [9]. Our case demonstrates that recognition of an illdefined tumor margin is a key observation that is useful for early diagnosis. Microscopic assessment of the slide from our patient revealed a transitional area between the fibroadenoma lesion and the cancerous lesion. The assessment demonstrates the beneficial impact of tracing the boundary of the tumorous part of the lesion.

Whether fibroadenoma is a risk factor for cancer is controversial. MacDivitt et al reported that the risk of breast cancer increased by $70 \%$ in a breast with fibroadenomas [8]. Furthermore, Diaz et al described 105 patients with breast cancers arising in a fibroadenoma [3]. On the other hand, some reports have failed to 
demonstrate a significant increase in breast cancers in women with fibroadenomas [11]. Dupont et al reported that despite the lack of an increased risk of breast cancer in patients with an uncomplicated breast fibroadenoma, an increased risk is observed in patients with breast fibroadenomas associated with cysts, sclerosing adenosis, epithelial calcifications, or papillary apocrine changes [7]. Although it remains unclear if breast cancer is likely to develop in a breast with fibroadenoma, breast surgeons should be aware of these cases [12].

In conclusion, we presented a patient with a 5-mm breast cancer that developed in the margin of a 7-mm fibroadenoma. Careful examination of the margin of the tumor is essential for the early detection of malignant changes.

\section{Declarations}

Ethics approval and consent to participate and Consent for publication

All procedures performed in studies involving human participants were in accordance with the 1964 Helsinki declaration and its later amendments or comparable ethical standards. We obtained written informed consent for publication from the patient. Ethical board approval of a case report is waived in our institution.

Availability of data and materials

The datasets used and/or analyzed during this study are available from the corresponding author on reasonable request.

Competing Interests

The authors have no conflicts to declare.

\section{Funding}

No funding to be declared.

\section{Authors' contributions}

KE analyzed and interpreted the patient data and was a major contributor in writing the manuscript. YH and KD analyzed and interpreted the patient data. SM performed the histological examination. KT revised the manuscript. All authors read and approved the final manuscript.

\section{Acknowledgments}

We thank Mieko Nishikiori and Yuka Suzuki for their secretarial assistance.

\section{References}


1. Kuijper A, Mommers EC, van der Wall E, van Diest PJ: Histopathology of fibroadenoma of the breast.Am J Clin Pathol 2001, 115:736-742.

2. Abe H, Hanasawa $K$, Naitoh H, Endo $Y$, Tani T, Kushima R: Invasive ductal carcinoma within a fibroadenoma of the breast.Int J Clin Oncol 2004, 9:334-338.

3. Diaz NM, Palmer JO, McDivitt RW: Carcinoma arising within fibroadenomas of the breast. A clinicopathologic study of 105 patients.Am J Clin Pathol 1991, 95:614-622.

4. Shiino S, Yoshida M, Tokura M, Watase C, Murata T, Jimbo K, Takayama S, Suto A, Satomi K, Miyagi Maeshima A, et al: Locally advanced triple negative breast cancer arising from fibroadenoma with complete response to neoadjuvant chemotherapy: A case report.Int J Surg Case Rep 2020, 68:234238.

5. Iwamoto M, Takei H, lida S, Yamashita K, Yanagihara K, Kurita T, Tsuchiya S, Kanazawa Y, Uchida E: Contralateral breast cancer adjacent to a fibroadenoma: report of a case.J Nippon Med Sch 2014, 81:168-172.

6. Park CJ, Kim EK, Woo HY, Moon HJ, Yoon JH, Kim MJ: Breast Cancer Arising Adjacent to an Involuting Fibroadenoma: Serial Changes in Radiologic Features.J Breast Cancer 2015, 18:291-295.

7. Dupont WD, Page DL, Parl FF, Vnencak-Jones CL, Plummer WD, Jr., Rados MS, Schuyler PA: Longterm risk of breast cancer in women with fibroadenoma.N Engl J Med 1994, 331:10-15.

8. McDivitt RW, Stevens JA, Lee NC, Wingo PA, Rubin GL, Gersell D: Histologic types of benign breast disease and the risk for breast cancer. The Cancer and Steroid Hormone Study Group.Cancer 1992, 69:1408-1414.

9. Baker KS, Monsees BS, Diaz NM, Destouet JM, McDivitt RW: Carcinoma within fibroadenomas: mammographic features.Radiology 1990, 176:371-374.

10. Borecky N, Rickard M: Preoperative diagnosis of carcinoma within fibroadenoma on screening mammograms.J Med Imaging Radiat Oncol 2008, 52:64-67.

11. Worsham MJ, Raju U, Lu M, Kapke A, Botttrell A, Cheng J, Shah V, Savera A, Wolman SR: Risk factors for breast cancer from benign breast disease in a diverse population.Breast Cancer Res Treat 2009, 118:1-7.

12. Markopoulos C, Kouskos E, Mantas D, Kontzoglou K, Antonopoulou K, Revenas Z, Kyriakou V: Fibroadenomas of the breast: is there any association with breast cancer?Eur $\mathrm{J}$ Gynaecol Oncol 2004, 25:495-497.

\section{Figures}




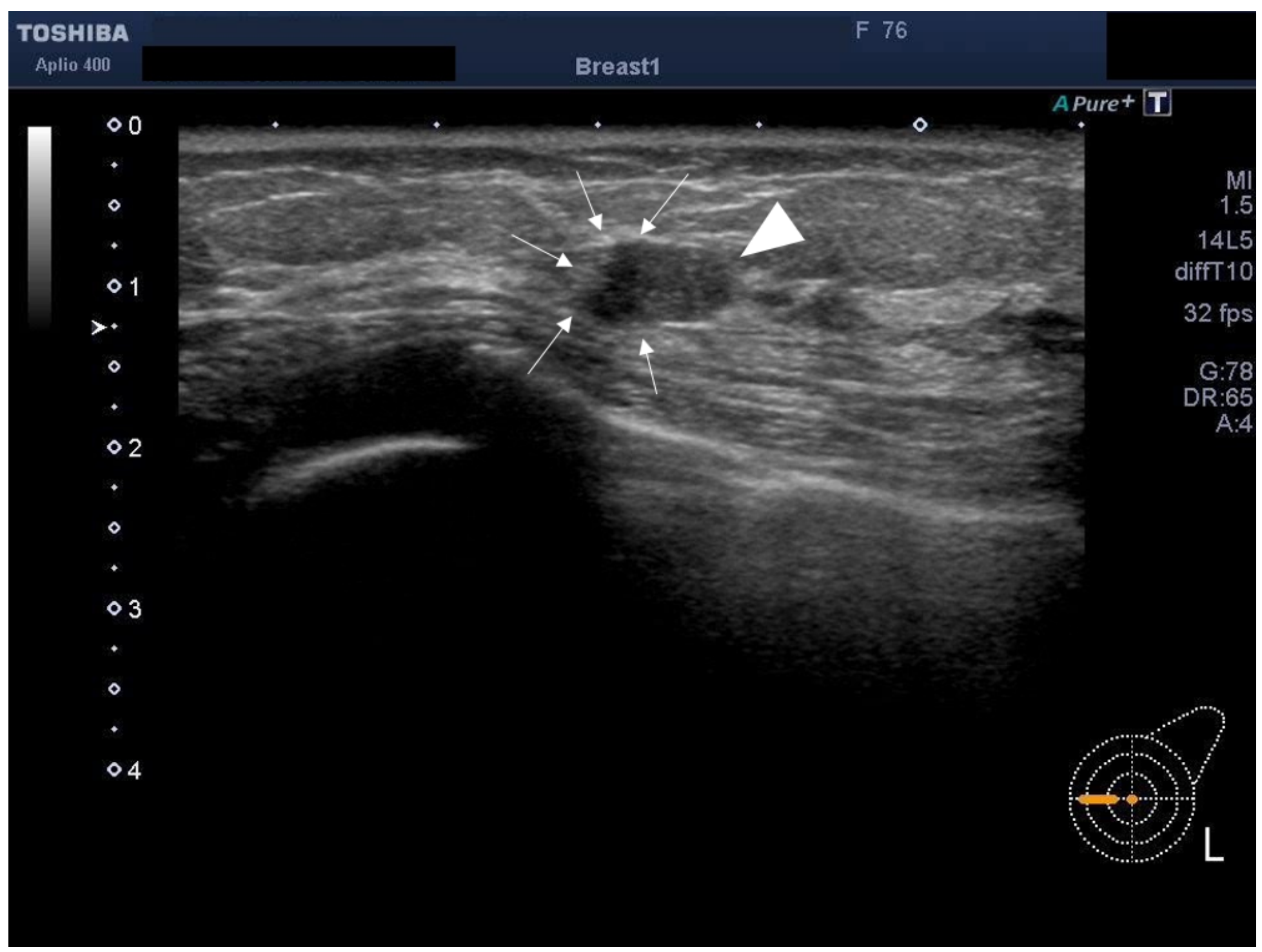

\section{Figure 1}

Ultrasonogram of this complex tumor. This tumor consists of 2 parts: a hypoechoic area with an irregular shape and unclear margins (fine arrows) and another isoechoic area with clear margins (arrowhead). 


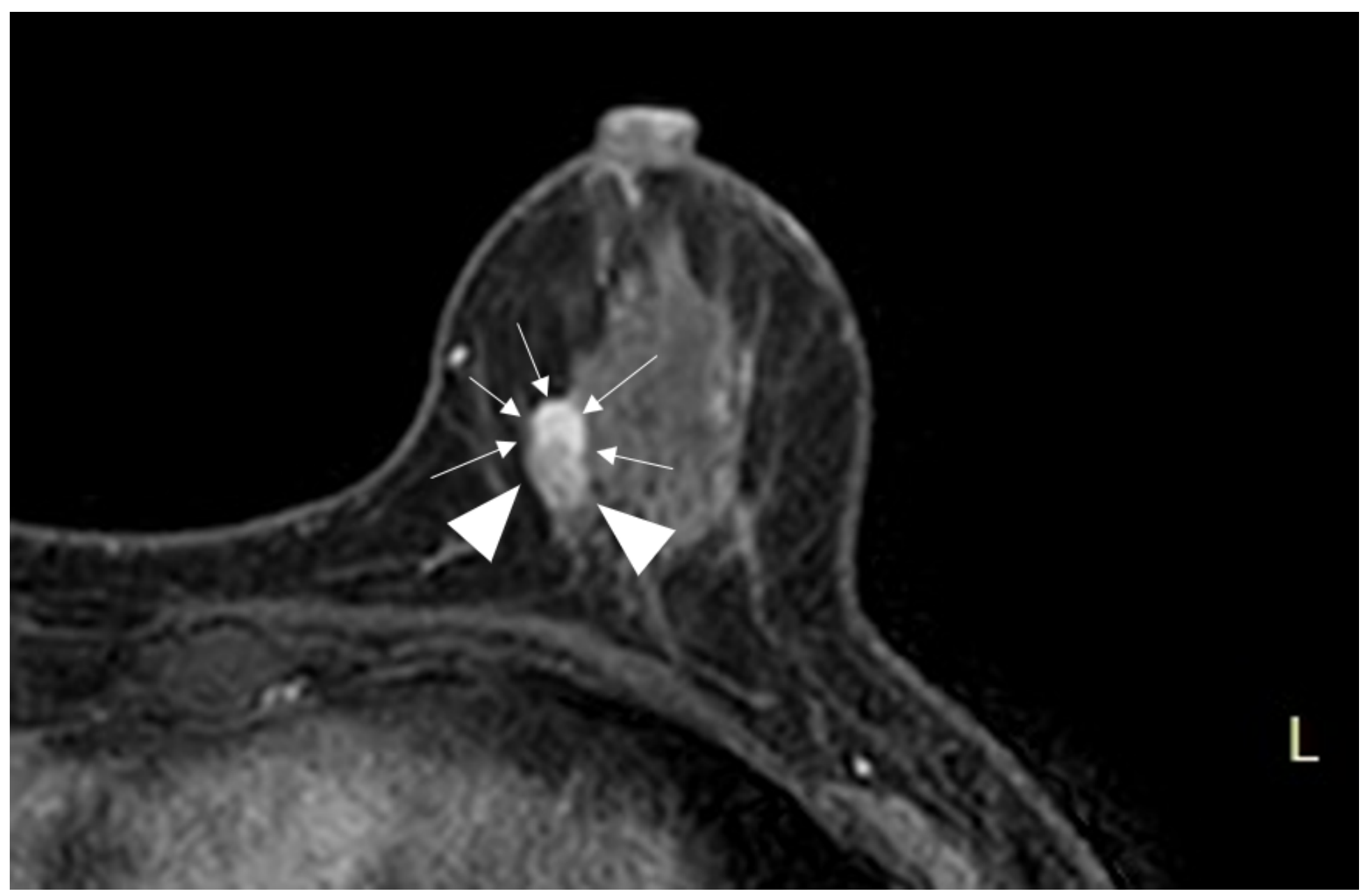

Figure 2

Contrast-enhanced magnetic resonance image demonstrates an oval tumor composed of 2 regions: an area of high vascularity (fine arrows) and an area of low vascularity (arrowheads). 


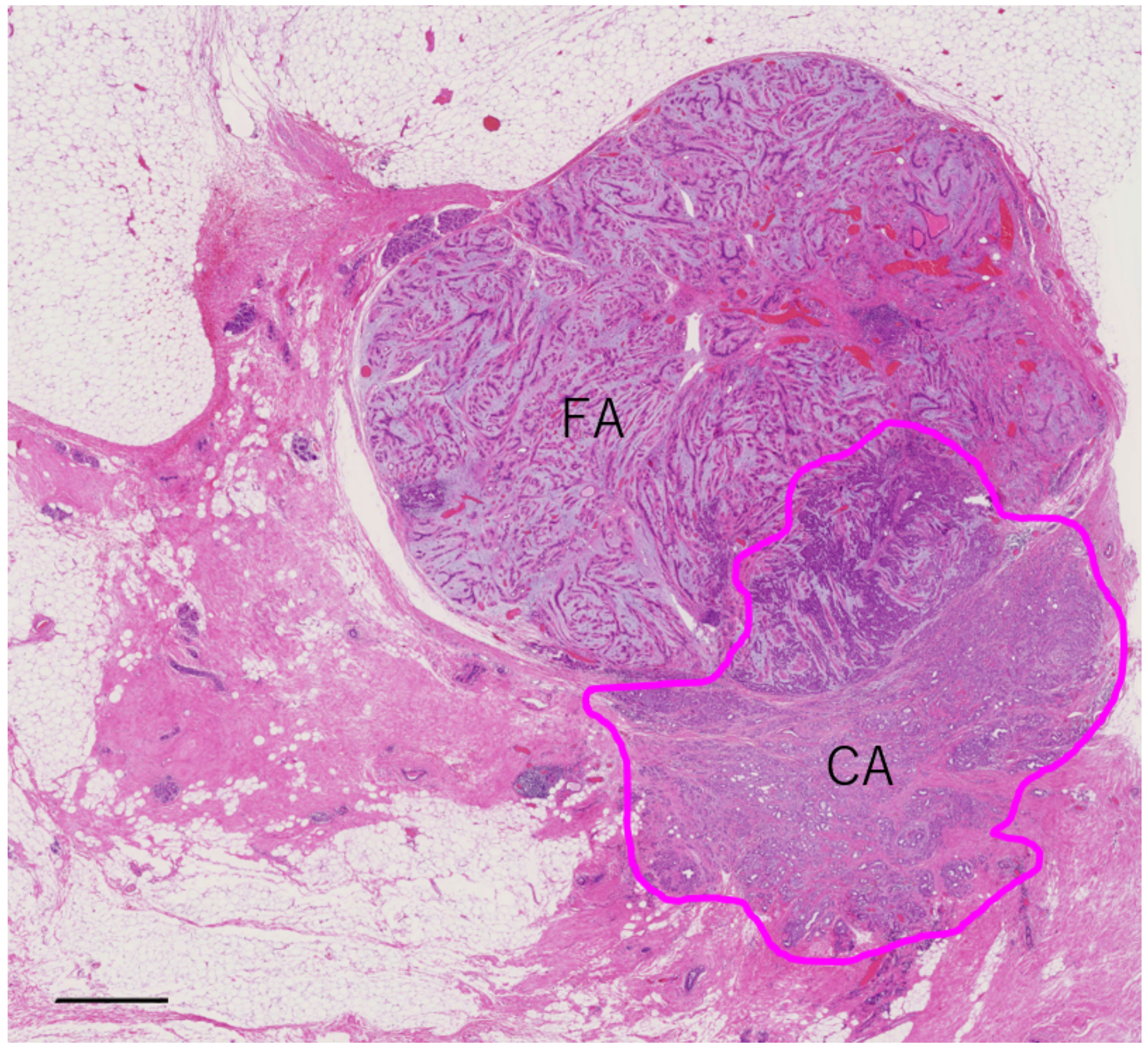

\section{Figure 3}

A cross section of the excised specimen containing the breast mass reveals that this tumor is comprised of a fibroadenoma and adenocarcinoma that overlap. The region of overlap consists of malignant cells. The adenocarcinoma lesion is surrounded by a pink line. "CA" and "FA" denote carcinoma and fibroadenoma, respectively. The black bar in the left lower corner of the photomicrograph indicates $1 \mathrm{~mm}$. 